\title{
Dihydroartemisinin inhibits EMT induced by platinum-based drugs via Akt-Snail pathway
}

\author{
Yuan Qin ${ }^{1,2, *}$, Guang Yang ${ }^{1, *}$, Meng Li ${ }^{1,2, *}$, Hui-Juan Liu ${ }^{2, *}$, Wei-Long Zhong ${ }^{1,2}$, Xue- \\ Qin Yan ${ }^{1,2}$, Kai-Liang Qiao, ${ }^{1,2}$, Jia-Huan Yang ${ }^{1,2}$, Deng-Hui Zhai, ${ }^{1,2}$, Wei Yang ${ }^{2}$, Shuang \\ Chen ${ }^{2}$, Hong-Gang Zhou ${ }^{1,2}$, Tao Sun ${ }^{1,2}$ and Cheng Yang ${ }^{1,2}$ \\ ${ }^{1}$ State Key Laboratory of Medicinal Chemical Biology and College of Pharmacy, Nankai University, Tianjin, China \\ ${ }^{2}$ Tianjin Key Laboratory of Molecular Drug Research, Tianjin International Joint Academy of Biomedicine, Tianjin, China \\ *These authors have contributed equally to this work \\ Correspondence to: Cheng Yang, email: Cheng.yang@nankai.edu.cn \\ Tao Sun, email: sunrockmia@hotmail.com \\ Keywords: dihydroartemisinin, EMT, Akt, Snail \\ Received: August 25, $2017 \quad$ Accepted: September 23, $2017 \quad$ Published: October 10, 2017 \\ Copyright: Qin et al. This is an open-access article distributed under the terms of the Creative Commons Attribution License 3.0 \\ (CC BY 3.0), which permits unrestricted use, distribution, and reproduction in any medium, provided the original author and source \\ are credited.
}

\section{ABSTRACT}

Artemisinin and its derivatives exhibit a high activity against a range of cancer cell types both in vitro and in vivo. In clinical practice, platinum-based anti-cancer chemotherapy is widely used to treat tumors. However, a large proportion of patients receiving these treatments will relapse because of metastasis and drug resistance. The purpose of this study is to explore the combinational anti-metastatic effect of platinum-based drugs and dihydroartemisinin (DHA). Both DDP and oxaliplatin (OXA) at low doses could induce epithelial-mesenchymal transition (EMT) in HCC. Meanwhile, co-administration of DHA could enhance DDP and OXA chemosensitivity in HCC and reverse drug resistance. DHA reversed the morphological changes induced by DDP or OXA and reversed the changes in EMT biomarkers induced by DDP and OXA in HCC in vitro and in vivo via AKT-Snail signaling. DHA significantly increased platinum-based drug sensitivity and suppressed EMT induced by platinum-based drugs via AKT-Snail signaling in HCC. DHA is expected to become the new adjuvant for chemotherapy.

\section{INTRODUCTION}

The era of platinum-based anti-cancer drugs was heralded by the clinical introduction of cisplatin, a square-planar platinum(II) complex whose anti-tumor properties were first reported by Rosenberg in 1969 [1]. Oxaliplatin (OXA), a third-generation platinum compound, exhibits promising activity against advanced HCC with tolerable toxicity [2]. A large population of HCC patients has been diagnosed with advanced disease; OXA-based chemotherapy is considered to be an important treatment choice for advanced-stage HCC [3]. However, biological deterioration after chemotherapy has recently been reported $[4,5]$. Chemotherapeutic agents enhanced metastatic potential in HCC and other cancer cell types both in vitro and in vivo. In clinical practice, recurrence and metastasis after surgery, as well as poor chemosensitivity, persist as a major barrier to successful chemotherapy in HCC [6].

Accumulated evidence indicates that epithelialmesenchymal transition (EMT) contributes to the "opposite effect" of platinum-based anti-cancer drugs $[3,7]$. EMT is a process characterized by the loss of typical epithelial characteristics and the acquisition of mesenchymal traits [8]. Undergoing EMT progress, HCC cells lose the connection of cell-cell, the contact of cell-matrix, and normal epithelial polarity while gaining mesenchymal characteristics to migrate and invade the surrounding matrix. Recent studies suggested that EMT was closely related to drug resistance, and drug resistance cells could acquire EMT features.

Artemisinin and its derivatives are sesquiterpene lactones derived from the sweet wormwood (Artemisia апnиа), which has been used in Chinese traditional 
medicine for thousands of years as a remedy for fever and chills. Following their discovery and development as anti-malarial drugs by Tu Youyou's group in the 1970s, artemisinin and its derivatives have come to represent the current front line in anti-malarial medicine [9]. Beyond these well-established antimalarial properties, there is accumulating evidence demonstrating that artemisinin and its derivatives possess cytotoxic effects against many human cancer cell types both in vitro and in animal experiments in vivo [10]. Depending on the cell line and experimental system, artemisinin affects a variety of processes in cancer cells, such as cell proliferation, apoptosis, and cellular hormone secretion [11]. Dihydroartemisinin (DHA), which is the most active derivative of artemisinin, has been recently reported to possess a preferential effect on cancer cells [12].

Prior studies have revealed that platinum-based anticancer drugs activated AKT signal pathway and induced EMT of cancer cells [13, 14]. Furthermore, latest data also show that DHA can suppress migration and invasion in vitro and in vivo in different cancer types via different pathways [15-18]. The aim of the present study was to examine the anti-tumor effect of DHA via inhibition of platinum-based drug-induced EMT and to explain the mechanism of DHA in the inhibition of the EMT.

\section{RESULTS}

\section{DHA enhanced the effects of platinum-based drugs and reversed drug resistance in $\mathrm{HCC}$}

Using an MTT assay, we determined the effect of a $48 \mathrm{~h}$ treatment with DHA, OXA, DDP, and DHA combined with OXA or DDP on cell viability. DHA, OXA, and DDP reduced cell viability in a dose-dependent manner. Meanwhile, DHA could evidently enhance the effects of DDP and OXA in inhibiting HCC cell proliferation. Moreover, Compusyn software analysis showed that the combination index (CI) value of combined treatment group was less than 1 at different doses, which indicated the synergistic effect between DHA and DDP or OXA as shown in Figure 1A. Western blot results showed that the combination treatment decreased the expression of proliferating cell nuclear antigen (PCNA), which is a marker of cell proliferation as shown in Figure 1B (DHA at $25 \mu \mathrm{M}$, DDP at $5 \mu \mathrm{M}$ and OXA at $5 \mu \mathrm{M})$. Live/dead assay was used to explore the effect of DHA $(25 \mu \mathrm{M} \approx$ $1 / 20 \operatorname{IC} 50), \operatorname{DDP}(5 \mu \mathrm{M} \approx 1 / 15 \operatorname{IC} 50)$ and $\mathrm{OXA}(5 \mu \mathrm{M} \approx$ $1 / 10$ IC50) on HCC. The percentage of cell death in the combination treatment groups was significantly increased compared with the other groups, as shown in Figure 1C. Chromatin condensation and nuclear fragmentation were widely observed in the combination treatment groups compared with single application, indicating an apoptosisinducing effect of the combination treatment group (DHA at $25 \mu \mathrm{M}$, DDP at $5 \mu \mathrm{M}$, and OXA at $5 \mu \mathrm{M}$ ) as shown in
Figure 1D. Moreover, DHA could reverse drug resistance of DDP and OXA in DDP-resistant cells(SMMC-7721/ DDP, HepG2/DDP and PLC/PRF/5/DDP) as shown in Figure 1E.

\section{DHA inhibits migration and invasion induced by low dose DDP/OXA}

We further characterized the morphological changes with an optical microscope and a scanning electron microscope. As shown in Figure 2A and 2B, low doses of DDP and OXA led to the extension of pseudopodia and changes in microfilament structure. High doses of DDP and OXA showed characteristic features consistent with apoptosis, including cell rounding and detachment. To further investigate the motility potential associated with the combination treatment, we did an in vitro wound healing assay. After the $24 \mathrm{~h}$ and $48 \mathrm{~h}$ treatments, the migration ability of cells treated only with DDP and OXA had increased. Meanwhile, the wound gap was wider in the combination treatment groups, indicating that the combination treatment inhibits the motility of SMMC-7721, HepG2 and PLC/PRF/5 cells (Figure 2C). Using a Boyden chamber, we determined changes in cell invasiveness after $24 \mathrm{~h}$. As shown in Figure 2D, DHA slightly reduced the number of cell invasions through the Matrigel-coated filter as compared to the control group. OXA and DDP increased the cell migration ability. The number of cell invasions through the Matrigel-coated filter was least in the combination treatment groups; therefore the combination treatment markedly inhibited the invasion of SMMC-7721, HepG2 and PLC/PRF/5 cells.

\section{DHA reverses changes in EMT biomarkers and inhibits AKT/Snail pathway induced by low dose DDP/OXA}

We examined the effect of the combination treatment on the expression of EMT biomarkers such as E-cadherin and vimentin. Western blot and immunofluorescence double staining results showed that the E-cadherin level has slightly decreased and the vimentin level has slightly increased in the DHA group. In the DDP and OXA groups, the EMT process has been promoted, the E-cadherin level decreased and vimentin level increased. However, in the combination treatment groups, the E-cadherin level significantly increased, and the vimentin level significantly decreased, demonstrating that the combination treatment effectively inhibited EMT (Figure 3A and 3B).

ATK is a core target that OXA can activate to induce EMT. Moreover, both artemisinin and its derivatives, e.g., DHA and artesunate, can inhibit the AKT pathway. Moreover, DHA can also prevent liver fibrosis by modulating the AKT pathway. The phosphorylation ATK, which was induced by DDP or OXA, was downregulated by DHA. Moreover, the expression of Snail was decreased 
A

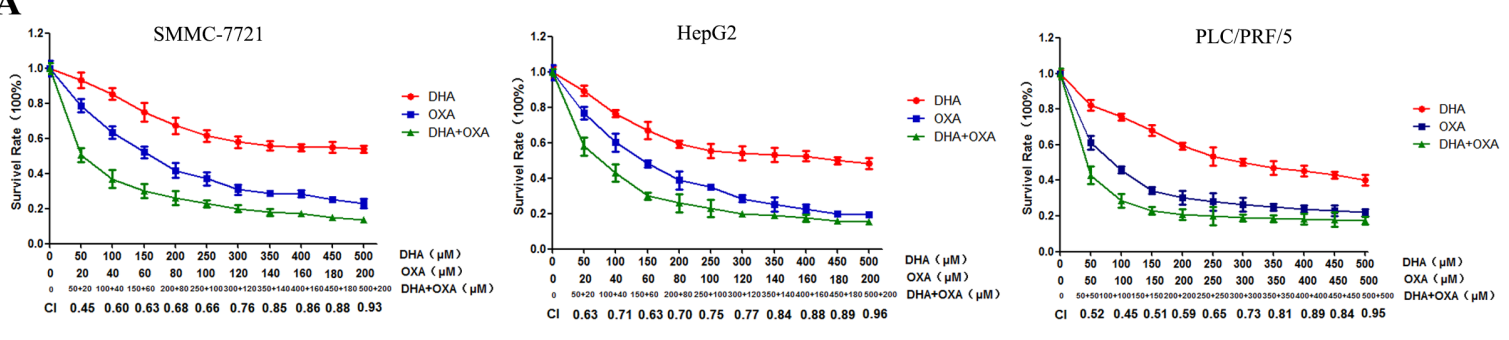

B
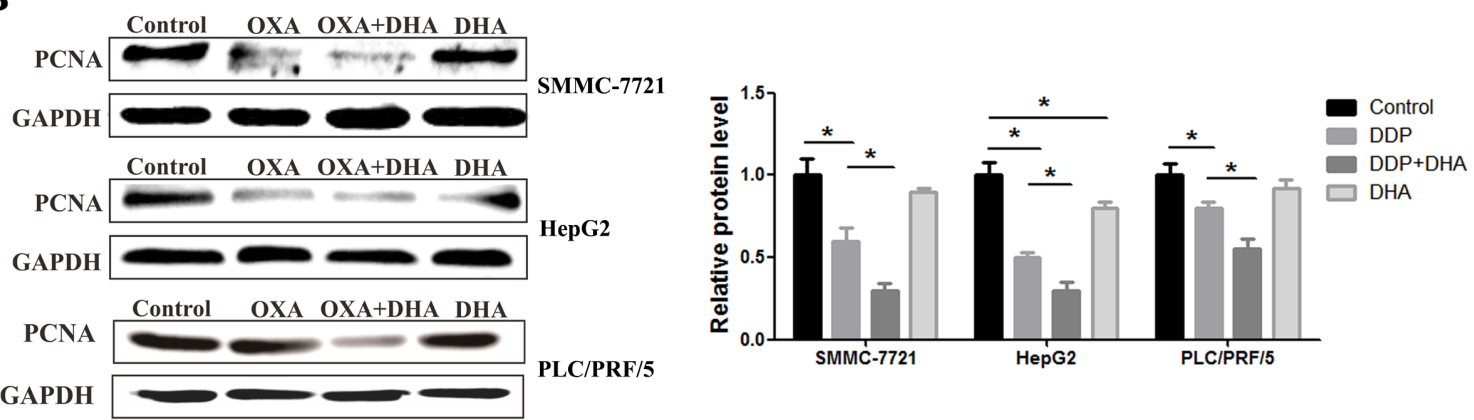

C
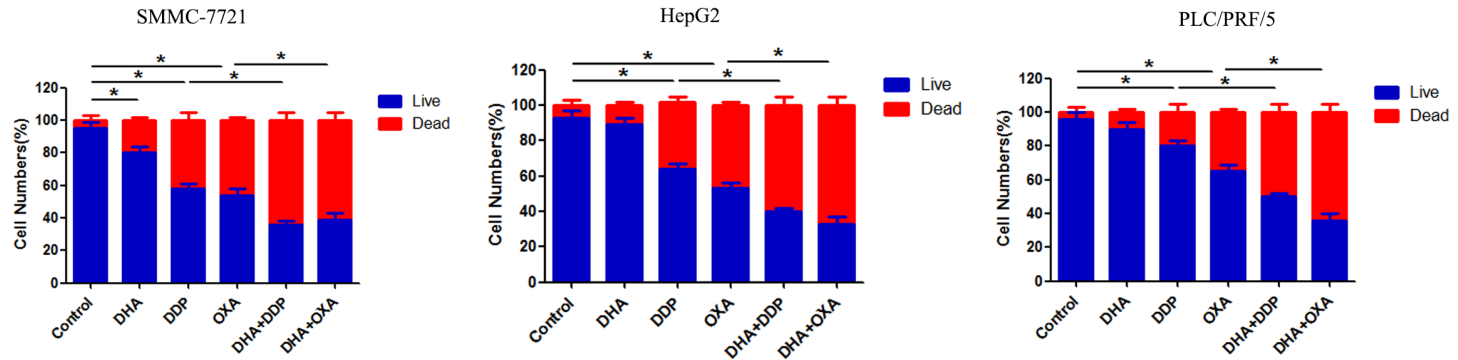

D
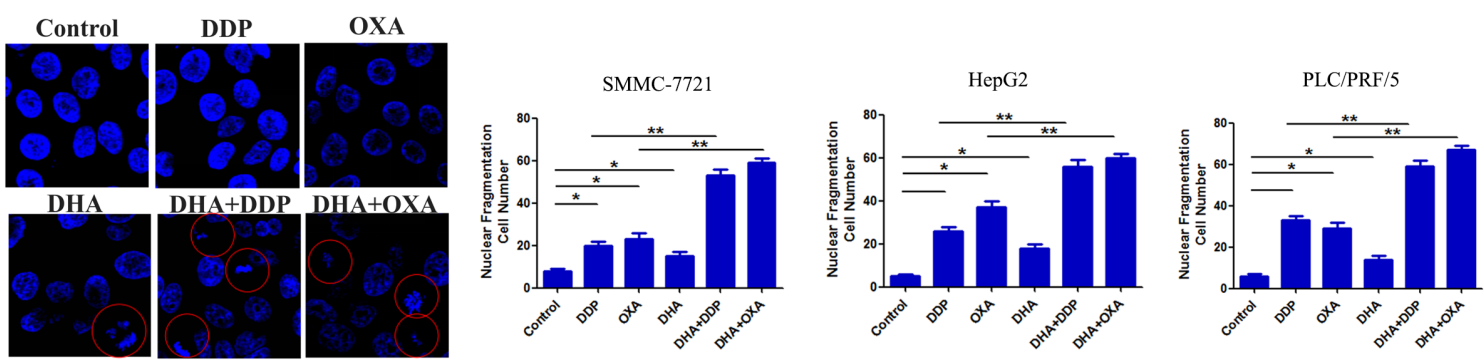

$\mathbf{E}$
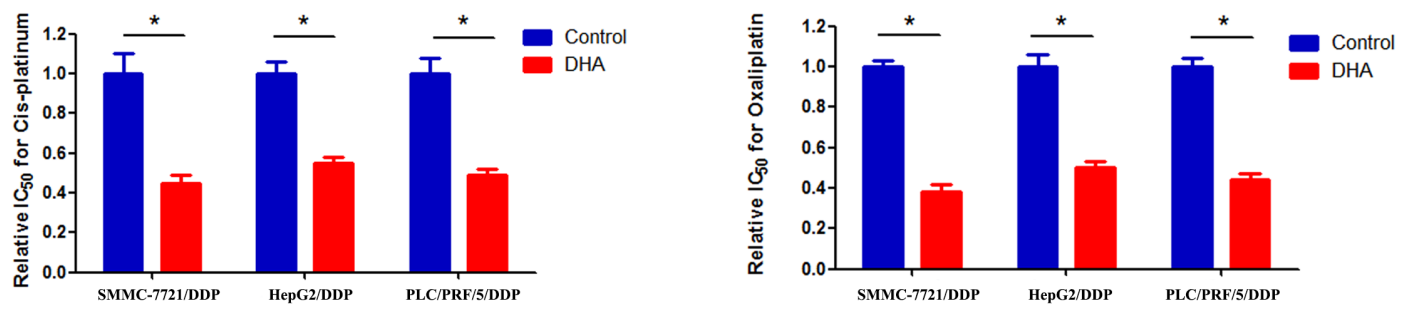

Figure 1: DHA enhanced the effects of platinum-based drugs and reverse drug resistance in HCC. (A) Survival of SMMC-7721, HepG2 and PLC/PRF/5 cells treated with the indicated amounts of DHA or platinum-based drugs or DHA combined with platinum-based drugs. (B) The expression of the proliferation marker in different groups. (C) The proportion of dead cells in different groups. (D) The proportion of nuclear fragmentation in different groups. (E) The relative IC50 value of DDP-resistant SMMC-7721, HepG2 and PLC/PRF/5 for DDP and OXA with or without DHA. Data are presented as means of three experiments, and error bars represent standard deviation $\left(* \mathrm{P}<0.05,{ }^{* *} \mathrm{P}<0.01\right)$. 
A
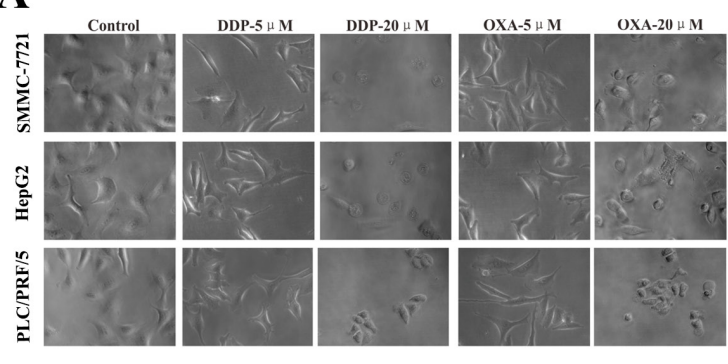

C
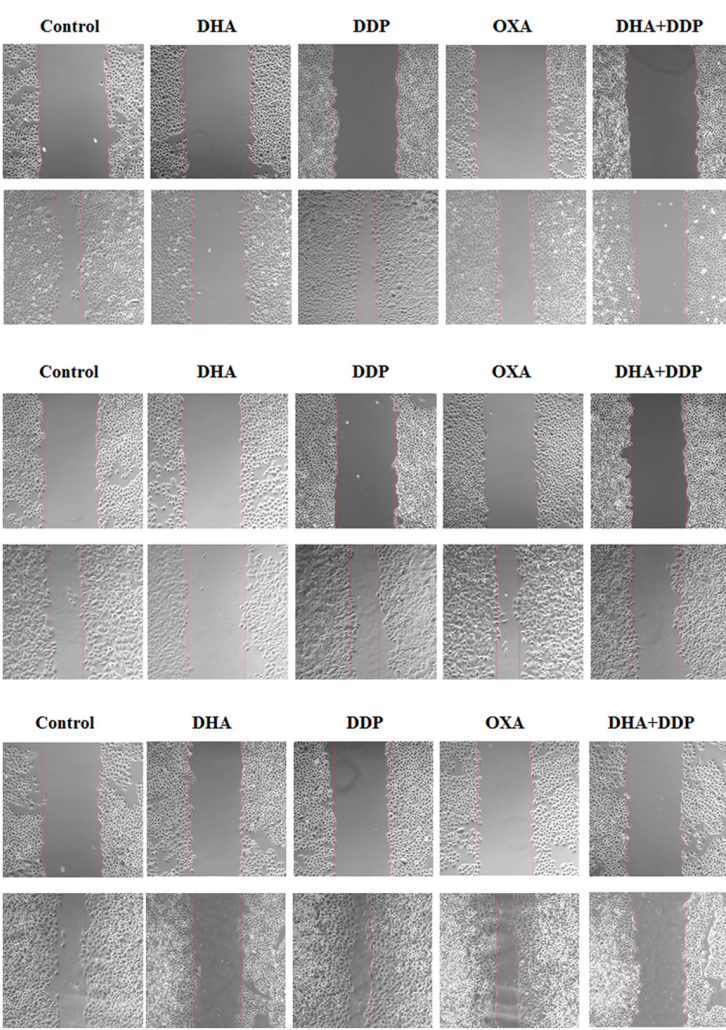

OXA
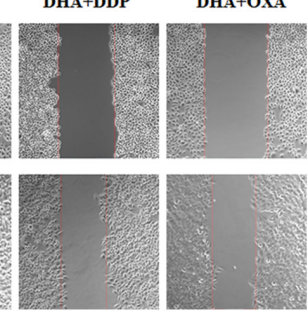

DHA+DDP
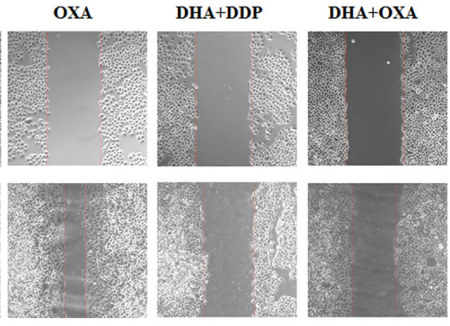

D

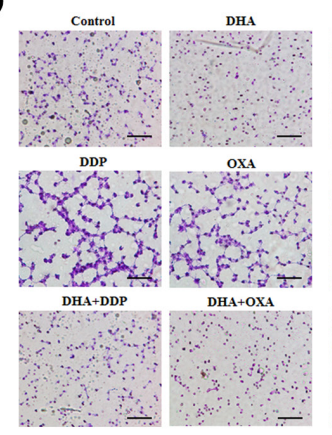

SMMC-7721
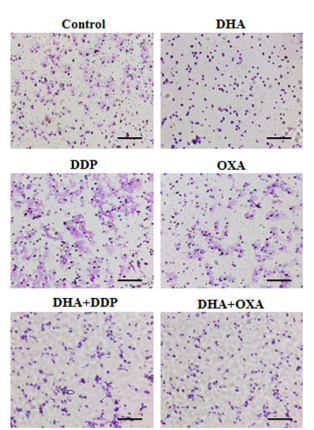

HepG2

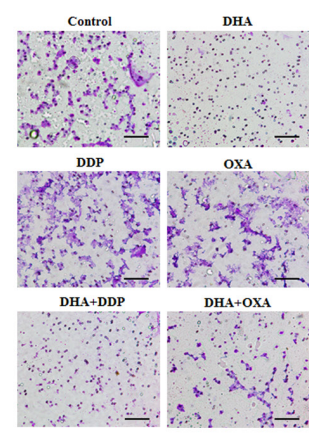

PLC/PRF/5
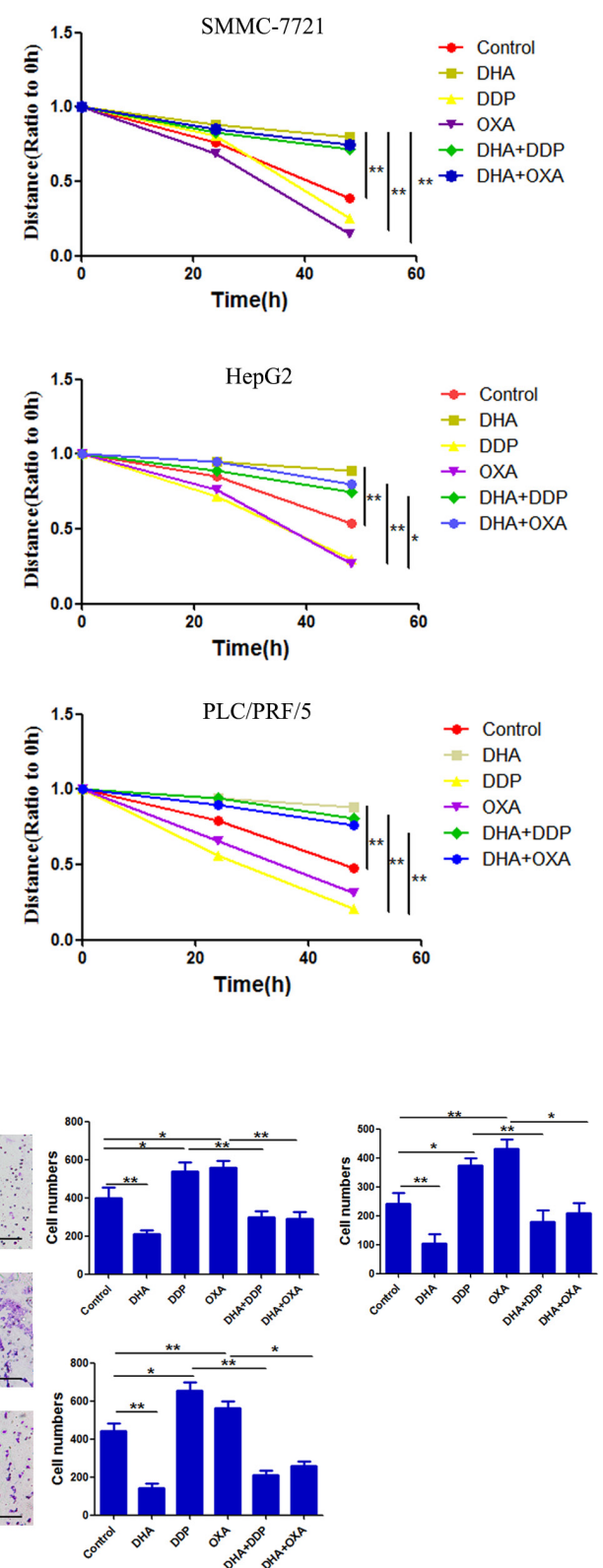

Figure 2: DHA inhibits migration and invasion induced by low dose DDP/OXA. (A) Typical images of cells in different groups using an optical microscope. (B) Typical images of cells in different groups using a scanning electron microscope. (C) Cell viability was inhibited after re-incubation in different groups for $48 \mathrm{~h}$. (D) Transwell chambers were utilized for the invasion assay, and images were obtained at $200 \times$ magnification. Data are presented as the means of three experiments, and error bars represent standard deviation $\left({ }^{*} \mathrm{P}<\right.$ $\left.0.05,{ }^{* *} \mathrm{P}<0.01\right)$. 
B
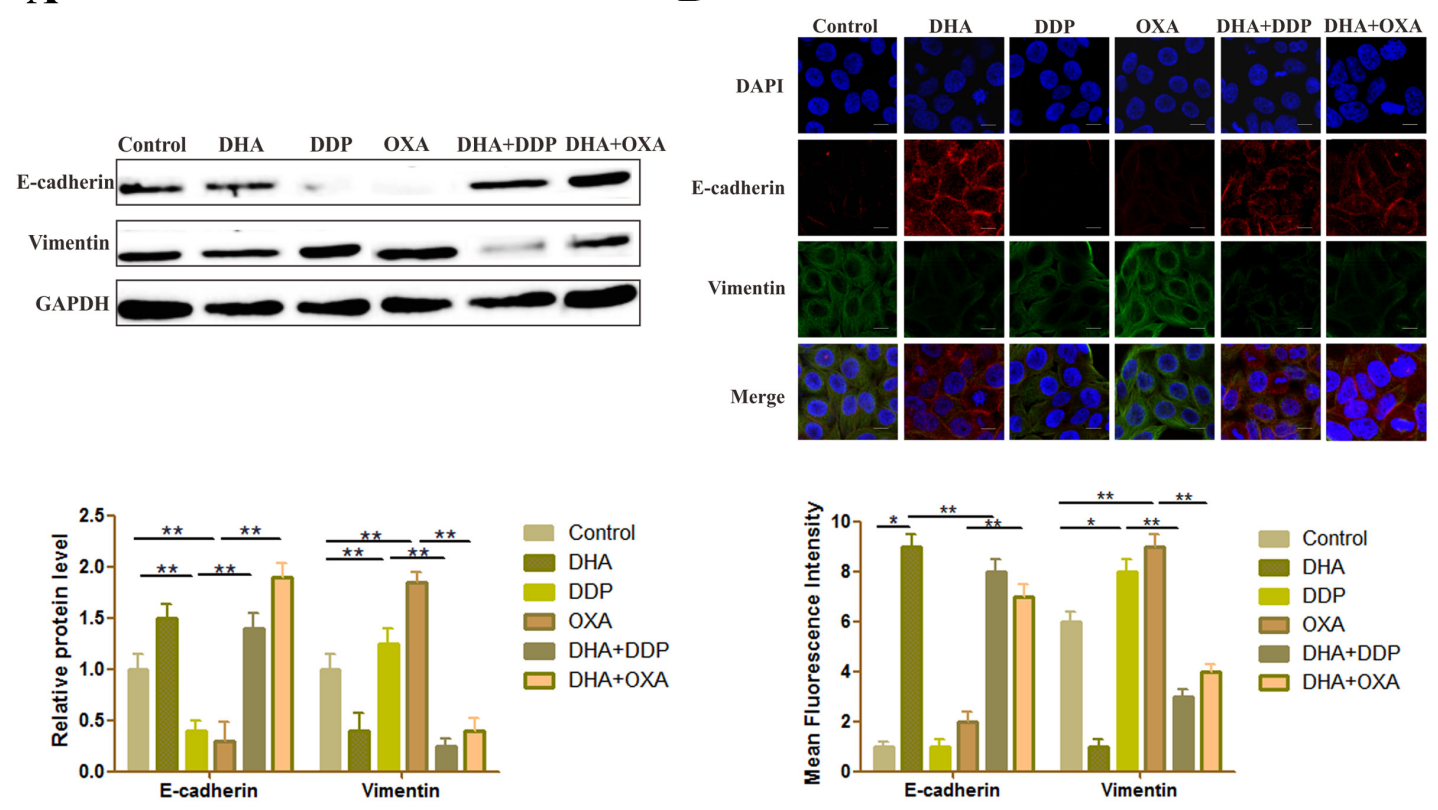

\section{$\mathbf{C}$}
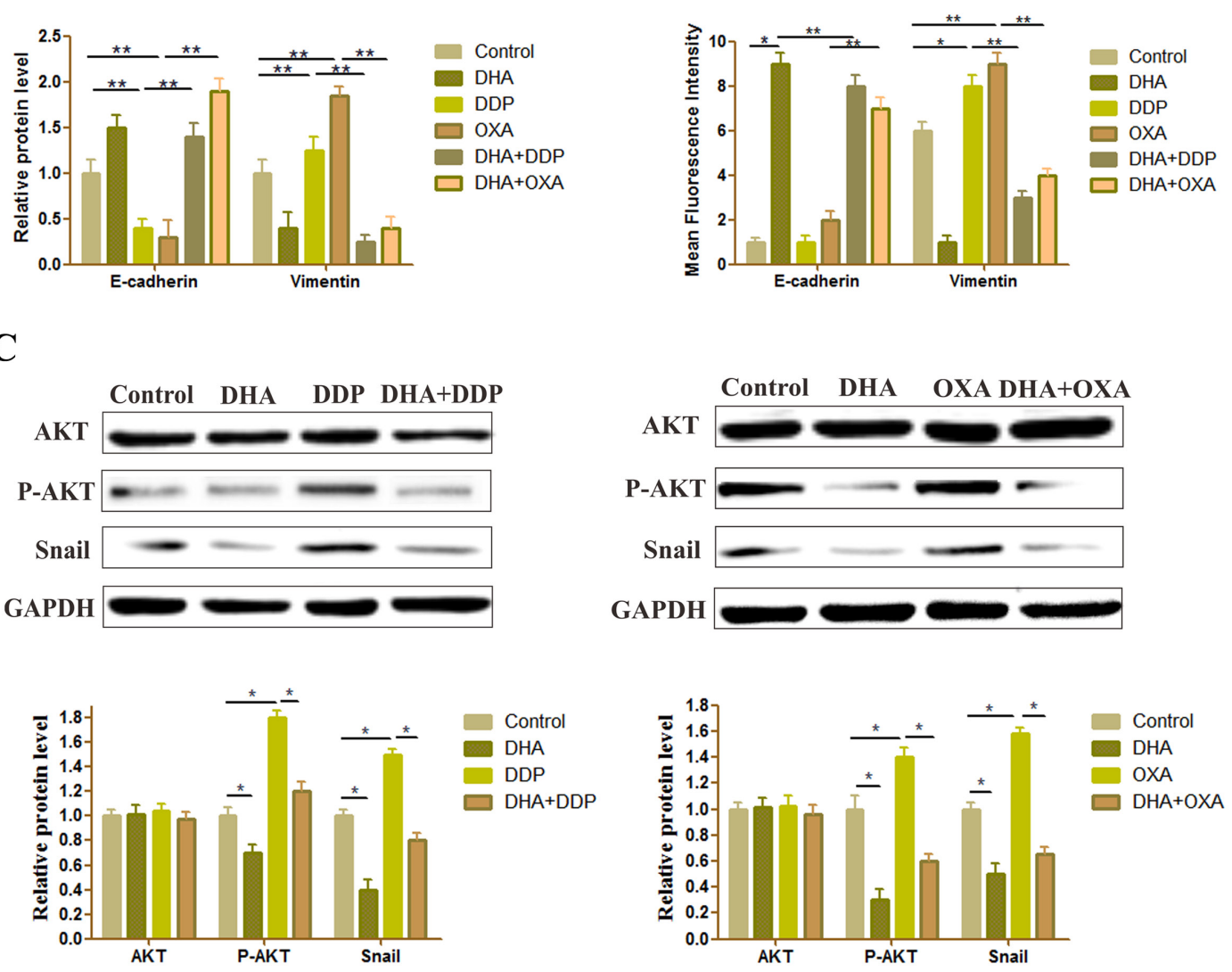

D

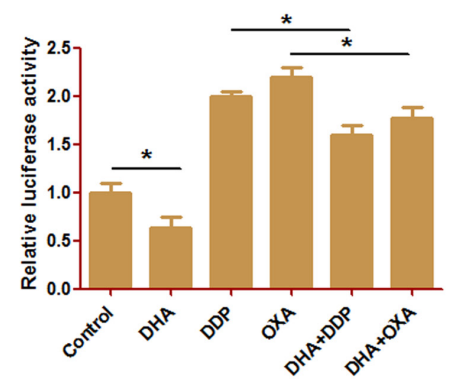

Figure 3: DHA reverses changes in EMT biomarkers and inhibits AKT/Snail pathway. (A) Protein expression level of E-cadherin and vimentin in HepG2 cells treated with different drugs. The GAPDH blot served as the loading control. (B) Typical images of immunofluorescent double staining for E-cadherin and vimentin in HepG2 cells treated with different drugs. Each experiment was performed in triplicate. The results are the means of the three experiments, and error bars represent the standard deviation. (C) Protein expression levels of AKT and P-AKT in HepG2 cells treated with different drugs. The GAPDH blot served as a loading control. (D) Dual-luciferase assay results of snail gene expression in HepG2 cells treated with different drugs. Data are presented as the means of three experiments, and error bars represent standard deviation $\left({ }^{*} \mathrm{P}<0.05\right.$ and $\left.{ }^{* *} \mathrm{P}<0.01\right)$. 
in the combination treatment groups compared with the DDP or OXA treatment groups (Figure 3C). The results of the reporter gene assay also showed that DHA inhibited the level of Snail, whether it was used as a single application or in combination with platinum-based drugs (Figure 3D).

\section{DHA enhanced the anti-tumor effects of DDP and OXA in a mouse xenograft model}

We next examined the effects of the combination treatment on HepG2 xenografts in BALB/c mice.
Compared with the control group, DDP and OXA treatment groups' body weight has reduced, and the combination treatment groups' body weight has increased. Tumor growth was slightly suppressed in DDP and OXA groups, and significantly suppressed in the combination treatment groups. These results strongly suggest that the combination treatment inhibits tumor growth (Figure 4A and $4 \mathrm{~B}$ ). Compared with the other groups, the numbers of tumors that shifted stoves decreased after the combination treatment (Figure 4C). Survival curves showed that the combination treatment increased mice survival rate compared with the single application groups (Figure 4D)
A

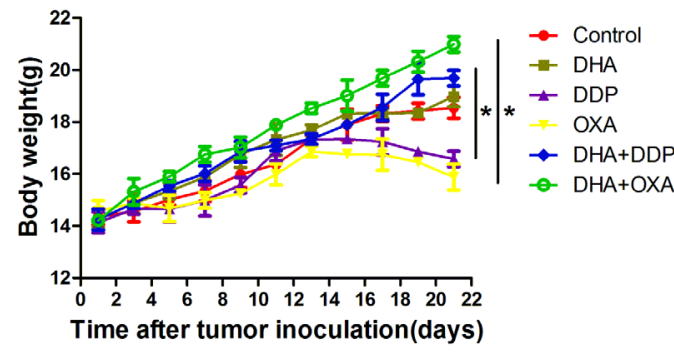

C
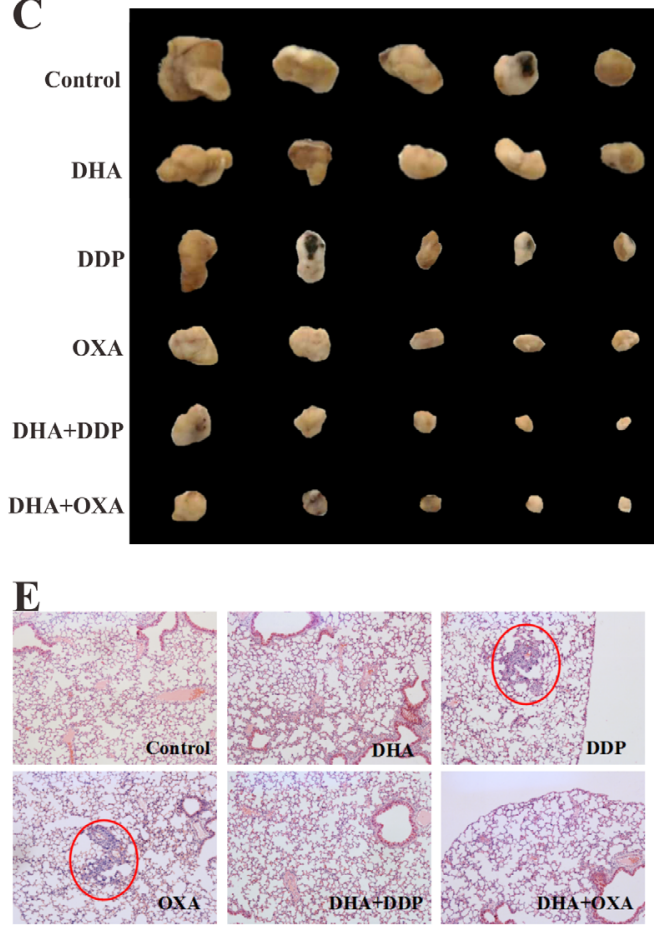

B

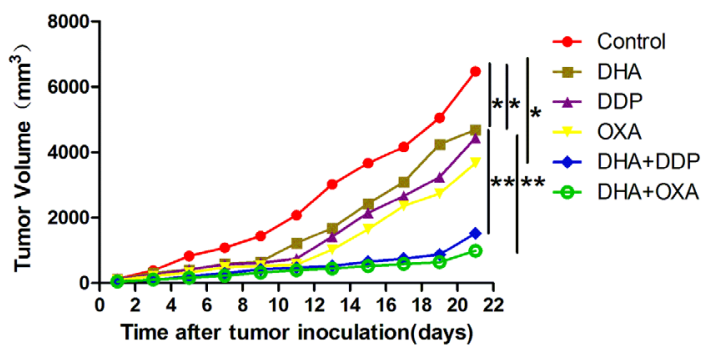

D
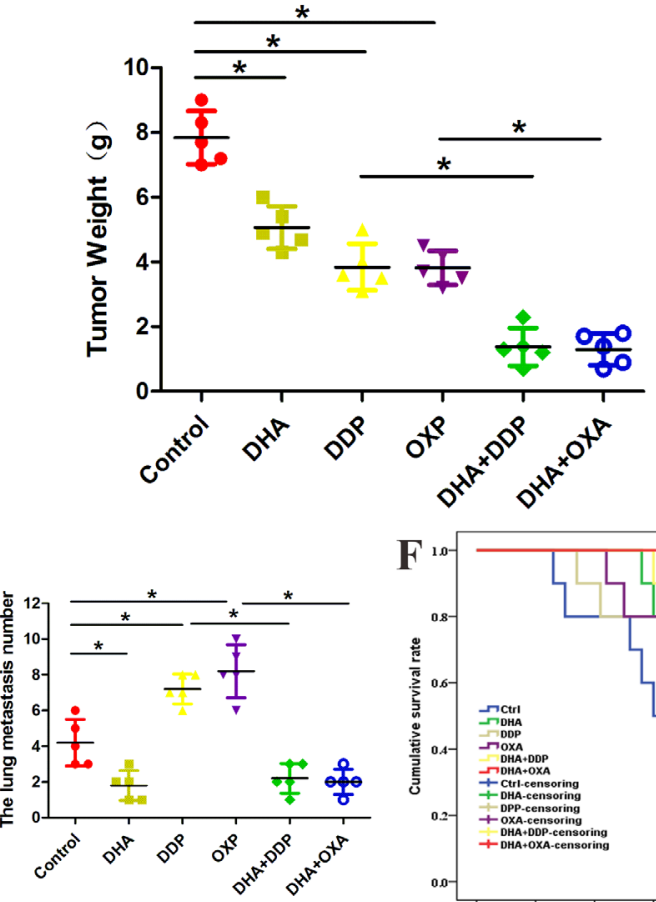

Figure 4: DHA enhanced the anti-tumor effects of DDP and OXA in a mouse xenograft model. (A) Body weights (g) of animals with HepG2 xenografts. (B) Changes in the tumor volume of HepG2 xenografts. (C) Typical images of HepG2 xenografts. (D) Tumor weights (g) of animals with HepG2 xenografts. (E) The numbers of tumors that shifted to the lungs in different groups. (F) The median survival time of animals with HepG2 xenografts in different groups. Data are presented as the means of three experiments, and error bars represent standard deviation $\left({ }^{*} \mathrm{P}<0.05\right.$ and $\left.{ }^{* *} \mathrm{P}<0.01\right)$. 


\section{DHA alters EMT marker levels and inhibits the NF-кB/Snail pathway induced by low dose DDP/ OXA in cancer tissues}

Expression of E-cadherin was enhanced in DHA and combination treatment groups relative to the control groups, and the combination group is more obvious. However, the vimentin level was increased in DDP and OXA treatment groups and decreased in the combination treatment groups (Figure 5A and 5C). Immunohistochemical staining for AKT, p-AKT and snail showed that the combination and the individual treatment

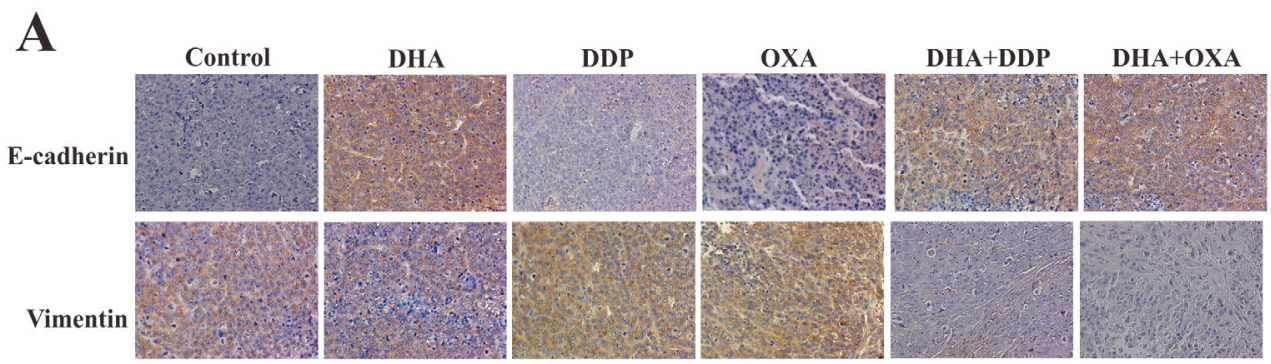

B

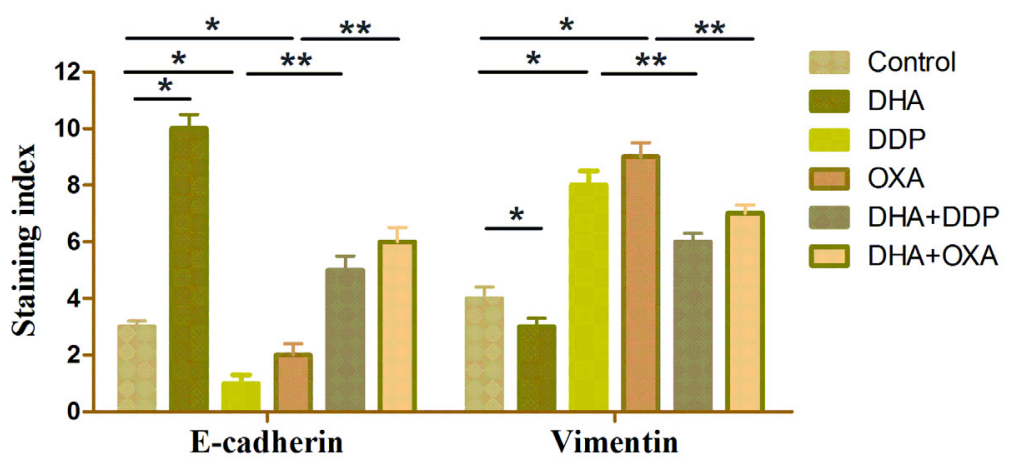

C

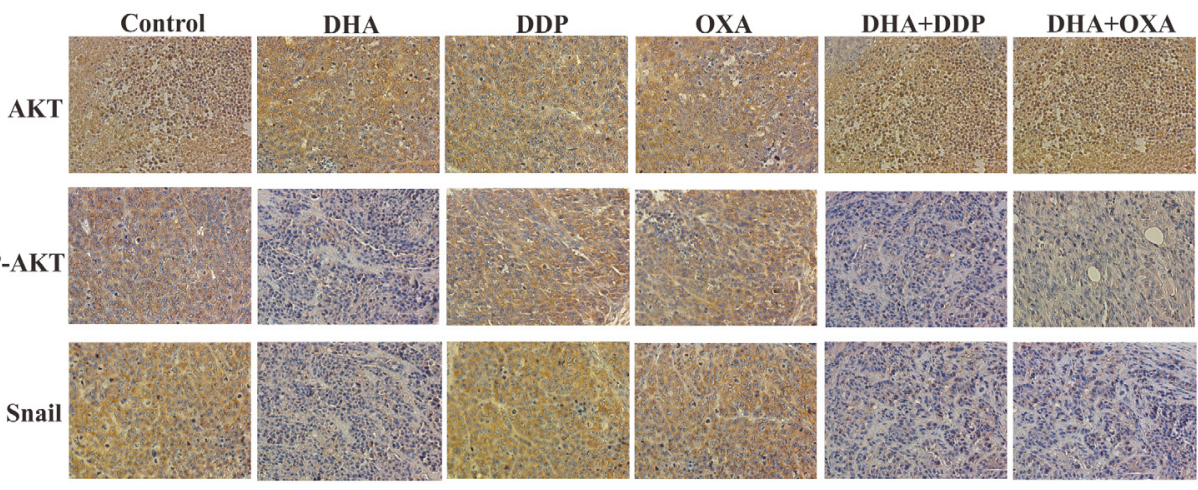

D

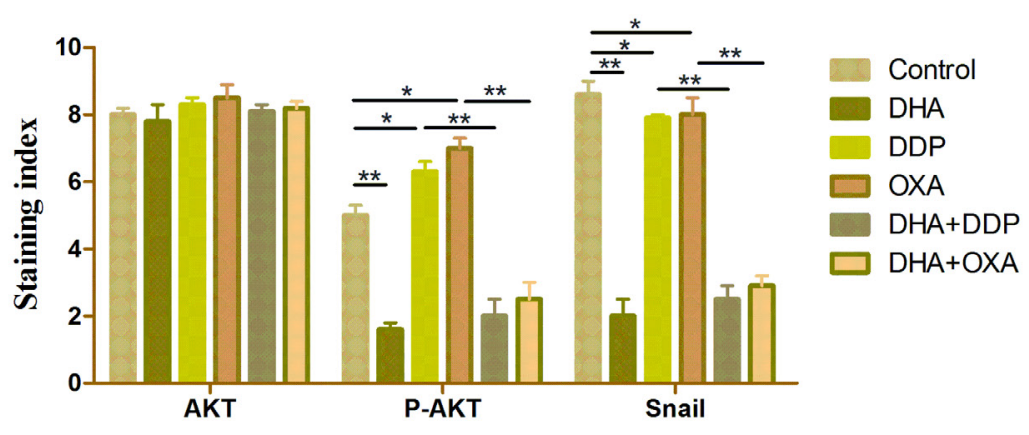

Figure 5: DHA alters EMT marker levels and inhibits the NF-кB/Snail pathway induced by DDP/OXA in cancer tissues. (A and C) Representative immunohistochemical staining of tumor samples showing E-cadherin and vimentin-positive staining. (B and D) Representative immunohistochemical staining of tumor samples showed AKT, P-AKT, and snail-positive staining. Data are presented as the means of three experiments, and error bars represent standard deviation $\left({ }^{*} \mathrm{P}<0.05,{ }^{* *} \mathrm{P}<0.01\right)$. 
groups had no significant difference in the total AKT levels. DDP and OXA treatments increased p-AKT and Snail levels, whereas DHA and combination treatments decreased p-AKT and Snail levels (Figure 5B and 5D).
STRING database was selected to examine several types of interactions between the control and artemisinin groups. Many functions are influenced by DHA, including tumor metastasis, proliferation and apoptosis,
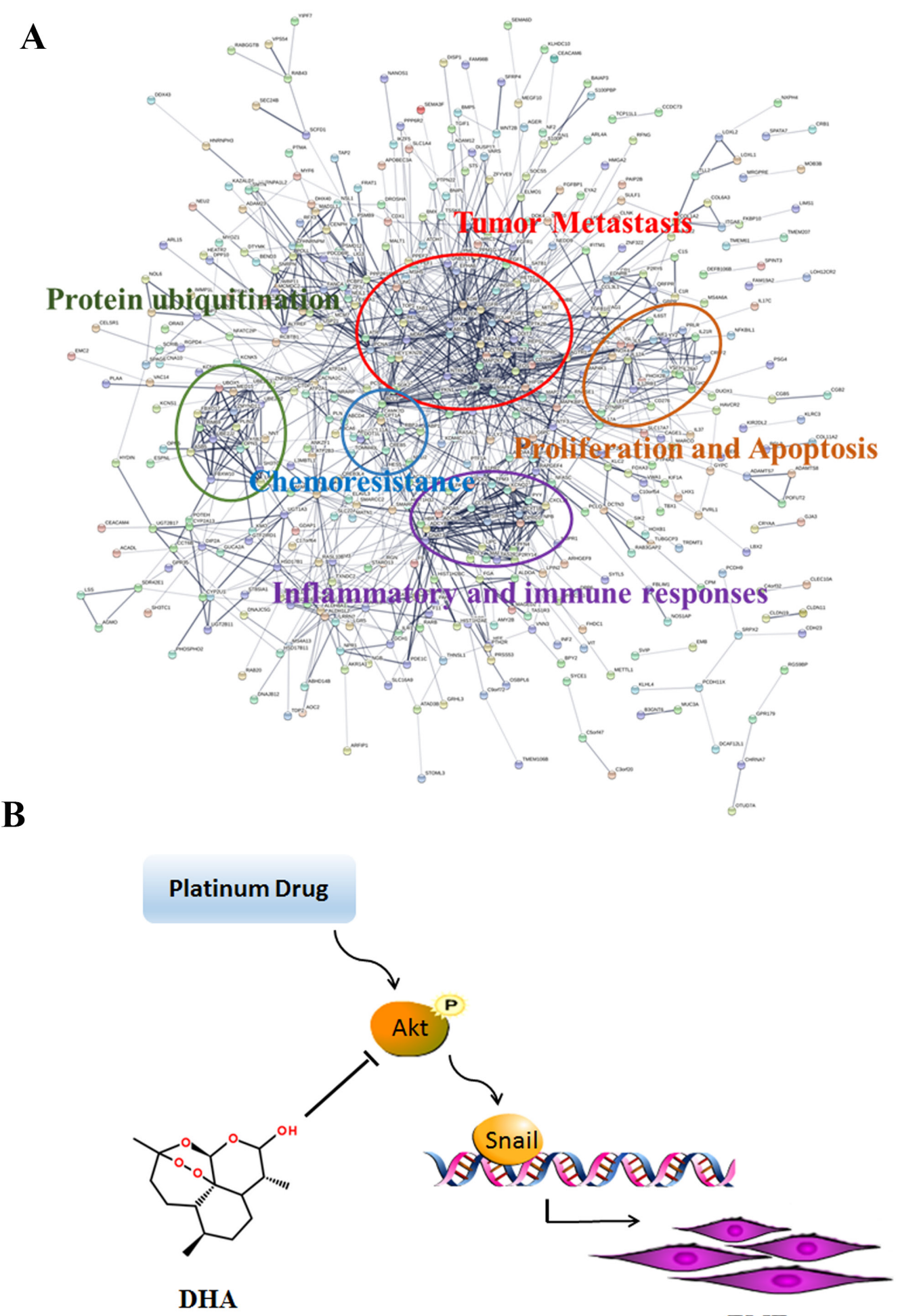

EMT

Figure 6: Effects of DHA in cancer cells. (A) DHA affects biological processes in cancer cells. (B) A model showing the role of DHA in EMT induced by platinum drugs. 
and chemoresistance (Figure 6A). In conclusion, DHA significantly increased platinum-based drug sensitivity and suppressed EMT induced by platinum-based drugs via AKT-Snail signaling in HCC (Figure 6B).

\section{DISCUSSION}

Although platinum-based anti-cancer chemotherapy is an important treatment choice for cancer, a large proportion of patients receiving these treatments will relapse [19, 20]. Many studies have been conducted to increase chemosensitivity in HCC patients. However, owing to little and limited understanding of chemoresistance mechanisms, the prognosis of $\mathrm{HCC}$ remains poor $[21,22]$.

Residual HCC after the OXA treatment demonstrated significantly increased metastasis in vitro and in vivo with the change of EMT markers and transcription factors $[23,24]$. EMT induced by platinumbased anti-cancer drug is an important event contributing to the development of resistance to chemotherapeutics and induction of metastasis [25]. EMT is associated with proliferation, invasion/migration, and metastasis in HCC [26]. Moreover, EMT renders tumor cells more resistant to chemotherapeutic drugs via $\mathrm{ABC}$ proteins, which is considered a major target of EMT and a potential contributor to drug resistance $[27,28]$. In accordance with previous reports, both DDP and OXA in low doses could alter cancer cells to EMT morphology and induce changes in EMT biomarkers in $\mathrm{HCC}$ in vitro and in vivo. Moreover, DDP and OXA increased the numbers of tumors that shifted stoves in vivo compared to the control group.

Since the first report of the possible anti-cancer properties of artemisinin in 1993, a large volume of studies have highlighted the potential of artemisinin and its derivatives as a novel therapeutic agent for cancer [2931]. Artemisinin co-treatment synergizes with or enhances the effects of various conventional chemotherapy drugs in a range of cancer types. Co-administration of DHA could enhance DDP and OXA chemosensitivity in HCC. Moreover, DHA could reverse drug resistance of DDP and OXA in DDP-resistant HHC. Moreover, co-administration of DHA could inhibit EMT induced by DDP and OXA. DHA reverses the morphological changes induced by DDP or OXA. DHA reversed changes in EMT biomarkers induced by DDP and OXA in HCC in vitro and in vivo. The co-administration groups inhibited the numbers of tumors that shifted stoves in vivo compared to the simple chemotherapeutic medicine groups. Effective and safe artemisinin combinations could potentially have anticancer uses [31, 32].

AKT is a core target that OXA can activate to induce EMT. The OXA treatment could lead to a high level of reactive oxygen species (ROS). ROS induced by therapeutic agent contributes to the formation of the intramolecular disulfide bond of Akt and the increase of the phosphorylation level of Akt, which results in the activation of Snail, mTOR, and ERK, and the induction of EMT and drug resistance of cancer cells [23, 33-35]. Both DDP and OXA could increase the level of phosphorylation of AKT and activate the AKT-Snail pathway in vitro and in vivo. In addition, co-administration groups decreased the level of phosphorylation of AKT and inhibit the AKT-Snail pathway in vitro and in vivo. Gene expression microarray results showed that DHA could affect many biological processes including tumor metastasis, proliferation, apoptosis, and chemoresistance in cancer cells, which is in agreement with our results and other people's findings [36, 37].

In conclusion, DHA significantly increased platinum-based drug sensitivity and suppressed EMT induced by platinum-based drugs via AKT-Snail signaling in HCC. DHA may be a potent platinum-based drugs sensitizer in HCC to improve the patients' chemotherapy response.

\section{MATERIALS AND METHODS}

\section{Cell culture}

The HepG2, PLC/PRF/5 and SMMC-7721 human liver cancer cell line was from KeyGen Biotech. All cells were passaged and maintained in RPMI 1640 containing $10 \%$ fetal bovine serum (Hyclone, USA) and maintained at $37^{\circ} \mathrm{C}$ with $5 \% \mathrm{CO}_{2}$ in a humidified atmosphere.

\section{Cell viability assay}

Cell viability was determined by the 3-(4-5-dimethylthiazol-2-yl)-2, 5-diphenyltetrazolium bromide dye reduction assay (MTT assay). The cells $\left(5 \times 10^{3}\right.$ cells/well $)$ were seeded into each well of a $96-$ well flat bottom plate. After overnight incubation, the cells were treated with various concentrations of drugs and the cells were cultured at $37^{\circ} \mathrm{C}$ with $5 \% \mathrm{CO}_{2}$ in a humidified atmosphere. The cells were divided into five groups, as follows: (1) the DHA-treated group $(0-500 \mu \mathrm{M}),(2)$ the OXA-treated group $(0-200 \mu \mathrm{M})$, (3) the DDP-treated group $(0-500 \mu \mathrm{M})$, (4) the DHA + OXA-treated group, and (5) the DHA + DDP-treated group. After the drug treatment for $48 \mathrm{~h}, 20 \mu \mathrm{L}$ MTT was added to each well and the cells were incubated for $4 \mathrm{~h}$. Following the subsequent removal of the supernatant, $150 \mu \mathrm{L}$ dimethyl sulfoxide (DMSO) was added to dissolve the formazan crystals. Absorbance was measured at $590 \mathrm{~nm}$ with a microplate reader (Multiskan ${ }^{\mathrm{TM}}$ FC, Thermo Scientific, Waltham, MA, USA).

\section{Wound-healing assay}

HepG2, PLC/PRF/5 and SMMC-7721 human liver cancer cells $\left(5 \times 10^{5}\right.$ cells/well $)$ were grown to confluency 
in 48-well plates. Cell monolayers were scratched using a $200 \mu \mathrm{L}$ pipette tip to create a wound and then washed once with phosphate-buffered saline (PBS). The cells were divided into six groups, as follows: (1) the control group (solvent control), (2) the DHA-treated group $(25 \mu \mathrm{M})$, (3) the OXA-treated group $(5 \mu \mathrm{M})$, (4) the DDP-treated group $(5 \mu \mathrm{M}),(5)$ the DHA + DDP-treated group $(25 \mu \mathrm{M}$ DHA $+5 \mu \mathrm{M}$ DDP), and (6) the DHA + OXA-treated group (25 $\mu \mathrm{M}$ DHA $+5 \mu \mathrm{M}$ OXA). Photographs were taken at 24 and $48 \mathrm{~h}$ with a Nikon microscope.

\section{Invasion assays}

The invasive potential of HepG2, PLC/PRF/5 and SMMC-7721 human liver cancer cells was determined by a Matrigel invasion assay using polycarbonate membranes (8.0 $\mu \mathrm{m}$ pore size) (Corning, USA) in the upper chamber of 24-well Transwell culture chambers coated with Matrigel. Cells $\left(2 \times 10^{5}\right.$ cells $\left./ \mathrm{mL}\right)$ suspended in $200 \mu \mathrm{L}$ of a serum-free medium were placed in the upper chambers, and the lower chambers were filled with RPMI 1640 with $10 \%$ fetal bovine serum as the chemoattractant. The cells were divided into six groups as described in the woundhealing assay. After the incubation at $37^{\circ} \mathrm{C}$ for $24 \mathrm{~h}$, cells on the upper surface of the filter were removed using a cotton swab. Cells migrating or invading through the filter to the lower surface were fixed with $4 \%$ paraformaldehyde for $20 \mathrm{~min}$ and stained with $0.1 \%$ crystal violet for $10 \mathrm{~min}$. Migrated or invaded cells were viewed and photographed under a phase-contrast microscope and counted in five fields (at 100× magnification).

\section{Immunofluorescence assays}

HepG2 human liver cancer cells $\left(2 \times 10^{5}\right.$ cells $\left./ \mathrm{mL}\right)$ were seeded into 24-well plates. The cells were divided into six groups as described in the wound-healing assay. After the incubation for $24 \mathrm{~h}$, cells were washed twice in PBS, fixed in $10 \%$ cold formalin $\left(-20^{\circ} \mathrm{C}\right)$, and then blocked with FBS (5\% BSA and 0.1\% Tritonx-100) for $1 \mathrm{~h}$. The cells were then incubated in the same solution containing primary antibodies specific for E-cadherin (1:100 dilution) and vimentin (1:100 dilution) for $1 \mathrm{~h}$ at room temperature. After three washes with phosphatebuffered saline (PBS), the cells were incubated in a secondary antibody (1:200 dilution) for $30 \mathrm{~min}$ at room temperature, incubated with DAPI for $10 \mathrm{~min}$ at room temperature, washed twice with PBS, and then observed using a high-content screening (HCS) system (Thermo Fisher, USA).

\section{Western blot analysis}

HepG2 human liver cancer cells were grown to confluence in 6-well plates and grown to $40-50 \%$ confluency. The cells were divided into six groups, as described in the wound-healing assay. After incubation for
$24 \mathrm{~h}$, the cells were washed twice with cold PBS and then harvested with a rubber scraper. After centrifugation, $50 \mu \mathrm{g}$ of total cellular lysates was mixed with SDS sample buffer, boiled for $10 \mathrm{~min}$ and then subjected to electrophoresis on $12 \%$ SDS-polyacrylamide gels. Proteins in each gel were transferred to PVDF membranes (Millipore, Billerica, MA, USA). blocked with TBST containing 5\% skim milk powder, and then incubated overnight at $4{ }^{\circ} \mathrm{C}$ with primary antibodies against E-cadherin (1:1000), vimentin (1:1000), and GAPDH (1:3000). The membranes were washed with TBST thrice for $10 \mathrm{~min}$ each and incubated with an appropriate HRP-conjugated secondary antibody for $1 \mathrm{~h}$ at room temperature. Protein bands were detected by the enhanced chemiluminescence detection system.

\section{Cell activation and intracellular staining}

HepG2, PLC/PRF/5 and SMMC-7721 human liver cancer cells $(20,000$ cells/well $)$ were seeded in each well of a 96-well plate. The cells were divided into six groups as described in the wound-healing assay. Cells were collected and washed with phosphate buffer saline. Staining with LIVE/DEAD Fixable Dead Cell Stain Kit (Molecular Probes) was performed before fixation to allow gating on viable cells. The percentage of live and dead cells was determined by flow cytometry.

\section{Scanning electron microscopy (SEM)}

Cells were seeded into 24-well plates and grown to $40-50 \%$ confluency. After overnight incubation, the cells were divided into five groups: (1) the control group (solvent control), (2) the DDP-treated group (5 $\mu \mathrm{M})$, (3) the DDP-treated group $(20 \mu \mathrm{M})$, (4) the OXAtreated group $(5 \mu \mathrm{M})$, and (5) the OXA-treated group (20 $\mu \mathrm{M})$. After incubating for $24 \mathrm{~h}$, the cells were fixed and dehydrated in acetone/isoamyl acetate $(1: 1)$ and dried with a gradient concentration of acetonitrile. The samples were pasted onto the SEM Sample Stub using a carbon tape and the sample was coated with gold for $40 \mathrm{~s}$ and analyzed under a high-resolution scanning electron microscope (LEO 1530 VP, Germany).

\section{Animal studies}

A total of 30 male BALB/c mice (18-20 g) were purchased from the National Institute for Food and Drug Control or experimental animal center of the Military Medical Science Academy of the Chinese PLA. All animals in this experiment were well cared for. HepG2 xenografts of tumors $\left(1 \times 10^{6} / \mathrm{ml}\right)$ suspended in PBS were established by a subcutaneous injection into the flank. One day after tumor cell inoculation, the mice were randomly divided into 6 groups ( $n=5$ /group) with identical average body weight. After the tumors reached an approximate volume of $100 \mathrm{~mm}^{3}$, the mice were divided into six groups, as follows: (1) the control group (saline by oral 
gavage once a day), (2) the DHA group (40 mg/mL), (3) the OXA group (5 mg/mL), (4) the DDP group (5 mg/ $\mathrm{mL})$, (5) the DHA + DDP group (40 mg/mL DHA + 5 $\mathrm{mg} / \mathrm{mL} \mathrm{DDP}$ ), and (6) the DHA + OXA group (40 mg/ $\mathrm{mL}+5 \mathrm{mg} / \mathrm{mL}$ ). The volumes of the transplanted tumor were measured every day. At the end of the experiments, the body weights of mice were recorded and the tumor and lung tissues of mice were collected and stained with (H\&E).

\section{Immunohistochemical analysis}

Immunohistochemical detection was performed on paraffin-embedded slides of tumor sections. These procedures employed a previous method described by Qin et al [12]. The Akt, p-Akt, E-Cadherin, and vimentin antibodies were diluted to 1:100; PBS replaced the first antibody as the negative control. The positive antibody reaction was scored into four grades, according to the staining intensity, as follows: none (0), weak brown $(1+)$, moderate brown $(2+)$, and strong brown $(3+)$. The percentages of positive cells were divided into five classes based on the percentage of tumor cells stained: 0 for no cells, 1 for $1 \%-25 \%, 2$ for $25 \%-50 \%, 3$ for $50 \%-75 \%$, and 4 for $>75 \%$.

\section{Multidimensional liquid chromatography- tandem mass spectrometry}

HepG2 cells $\left(4 \times 10^{3}\right.$ cells $\left./ \mathrm{mL}\right)$ were seeded in a $100 \mathrm{~mm}$ dish to $70-80 \%$ confluence. The cells were then cultured in the presence $(25 \mu \mathrm{M})$ or absence of artemisinin for $24 \mathrm{~h}$. After cell lysis, samples were tested by using multidimensional liquid chromatography-tandem mass spectrometry.

\section{Statistical analysis}

All data are expressed as means \pm standard deviation. Comparisons between groups were performed by one-way analysis of variance followed by Bonferroni post hoc test (SPSS software package version 17.0, SPSS Inc., Chicago, IL, USA). The level of significance was set at $P<0.05$.

\section{CONFLICTS OF INTEREST}

The authors declare no conflicts of interest.

\section{FUNDING}

This study was funded by the National Natural Science Funds of China (Grant Nos. 81402973 and 81572838), Tianjin science and technology innovation system and the condition of platform construction plan (Grant No. 14TXSYJC00572), National Biomedical Special Project of International Innovation Park (Grant
Nos.13ZCZDSY02600 and 13ZCZDSY03300), Tianjin Natural Science and Technology Fund (Grant No.15JCYBJC26400), Foundation for the Author of National Excellent Doctoral Dissertation of China (Grant No. 201482) and Tianjin Research Program of Application Foundation and Advanced Technology (Grant No. 13JCYBJC39600), Tianjin Science and Technology Project (Grant No. 15PTGCCX00140 and Grant No. 2017ZX09306007).

\section{REFERENCES}

1. Rosenberg B, VanCamp L, Trosko JE, Mansour VH. Platinum compounds: a new class of potent antitumour agents. Nature. 1969; 222:385-386.

2. Wu Q, Qin SK, Teng FM, Chen CJ, Wang R. Lobaplatin arrests cell cycle progression in human hepatocellular carcinoma cells. J Hematol Oncol. 2010; 3:43.

3. Deng G, Zeng S, Ma J, Zhang Y, Qu Y, Han Y, Yin L, Cai C, Guo C, Shen H. The anti-tumor activities of Neferine on cell invasion and oxaliplatin sensitivity regulated by EMT via Snail signaling in hepatocellular carcinoma. Sci Rep. 2017; 7:41616.

4. Xiong W, Ren ZG, Qiu SJ, Sun HC, Wang L, Liu BB, Li QS, Zhang W, Zhu XD, Liu L, Wang WQ, Tang ZY. Residual hepatocellular carcinoma after oxaliplatin treatment has increased metastatic potential in a nude mouse model and is attenuated by Songyou Yin. BMC Cancer. 2010; 10:219.

5. Yamauchi K, Yang M, Hayashi K, Jiang P, Yamamoto N, Tsuchiya H, Tomita K, Moossa AR, Bouvet M, Hoffman RM. Induction of cancer metastasis by cyclophosphamide pretreatment of host mice: an opposite effect of chemotherapy. Cancer Res. 2008; 68:516-520.

6. Chow AK, Ng L, Lam CS, Wong SK, Wan TM, Cheng NS, Yau TC, Poon RT, Pang RW. The enhanced metastatic potential of hepatocellular carcinoma (HCC) cells with sorafenib resistance. PLoS One. 2013; 8:e78675.

7. Wen Q, Chen Z, Chen Z, Chen J, Wang R, Huang C, Yuan W. EphA2 affects the sensitivity of oxaliplatin by inducing EMT in oxaliplatin-resistant gastric cancer cells. Oncotarget. 2017; 8:47998-48011. https://doi.org/10.18632/ oncotarget. 18208 .

8. Qin Y, Zhang Q, Lee S, Zhong WL, Liu YR, Liu HJ, Zhao D, Chen S, Xiao T, Meng J, Jing XS, Wang J, Sun B, et al. Doxycycline reverses epithelial-to-mesenchymal transition and suppresses the proliferation and metastasis of lung cancer cells. Oncotarget. 2015; 6:40667-40679. https://doi. org/10.18632/oncotarget.5842.

9. Wang J, Zhang CJ, Chia WN, Loh CC, Li Z, Lee YM, He Y, Yuan LX, Lim TK, Liu M, Liew CX, Lee YQ, Zhang J, et al. Haem-activated promiscuous targeting of artemisinin in Plasmodium falciparum. Nat Commun. 2015; 6:10111.

10. Wang J, Zhang J, Shi Y, Xu C, Zhang C, Wong YK, Lee YM, Krishna S, He Y, Lim TK, Sim W, Hua ZC, Shen HM, Lin Q. Mechanistic investigation of the specific 
anticancer property of artemisinin and its combination with aminolevulinic acid for enhanced anticolorectal cancer activity. ACS Cent Sci. 2017; 3:743-750.

11. Chen X, Wong YK, Lim TK, Lim WH, Lin Q, Wang J, Hua Z. Artesunate activates the intrinsic apoptosis of HCT116 cells through the suppression of fatty acid synthesis and the NF-kappaB pathway. Molecules. 2017; 22:E1272.

12. Wang $\mathrm{Z}, \mathrm{Hu} \mathrm{W}$, Zhang JL, Wu XH, Zhou HJ. Dihydroartemisinin induces autophagy and inhibits the growth of iron-loaded human myeloid leukemia K562 cells via ROS toxicity. FEBS Open Bio. 2012; 2:103-112.

13. Aroui S, Dardevet L, Najlaoui F, Kammoun M, Laajimi A, Fetoui H, De Waard M, Kenani A. PTEN-regulated AKT/FoxO3a/Bim signaling contributes to Human cell glioblastoma apoptosis by platinum-maurocalcin conjugate. Int J Biochem Cell Biol. 2016; 77:15-22.

14. Qin Y, Zhao D, Zhou HG, Wang XH, Zhong WL, Chen S, Gu WG, Wang W, Zhang CH, Liu YR, Liu HJ, Zhang Q, Guo YQ, et al. Apigenin inhibits NF-kappaB and snail signaling, EMT and metastasis in human hepatocellular carcinoma. Oncotarget. 2016; 7:41421-41431. https://doi. org/10.18632/oncotarget.9404.

15. Tong Y, Liu Y, Zheng H, Zheng L, Liu W, Wu J, Ou R, Zhang G, Li F, Hu M, Liu Z, Lu L. Artemisinin and its derivatives can significantly inhibit lung tumorigenesis and tumor metastasis through Wnt/beta-catenin signaling. Oncotarget. 2016; 7:31413-31428. https://doi.org/10.18632/ oncotarget.8920.

16. Jiang J, Geng G, Yu X, Liu H, Gao J, An H, Cai C, Li N, Shen D, Wu X, Zheng L, Mi Y, Yang S. Repurposing the anti-malarial drug dihydroartemisinin suppresses metastasis of non-small-cell lung cancer via inhibiting NF-kappaB/ GLUT1 axis. Oncotarget. 2016; 7:87271-87283. https://doi. org/10.18632/oncotarget.13536.

17. Que Z, Wang P, Hu Y, Xue Y, Liu X, Qu C, Ma J, Liu Y. Dihydroartemisin inhibits glioma invasiveness via a ROS to P53 to beta-catenin signaling. Pharmacol Res. 2017; 119:72-88

18. Feng MX, Hong JX, Wang Q, Fan YY, Yuan CT, Lei XH, Zhu M, Qin A, Chen HX, Hong D. Dihydroartemisinin prevents breast cancer-induced osteolysis via inhibiting both breast caner cells and osteoclasts. Sci Rep. 2016; 6:19074.

19. Cunningham D, Atkin W, Lenz HJ, Lynch HT, Minsky B, Nordlinger B, Starling N. Colorectal cancer. Lancet. 2010; 375:1030-1047.

20. Li P, Zhang X, Wang H, Wang L, Liu T, Du L, Yang Y, Wang C. MALAT1 is associated with poor response to oxaliplatin-based chemotherapy in colorectal cancer patients and promotes chemoresistance through EZH2. Mol Cancer Ther. 2017; 16:739-751.

21. Xiong H, Ni Z, He J, Jiang S, Li X, He J, Gong W, Zheng L, Chen S, Li B, Zhang N, Lyu X, Huang G, et al. LncRNA HULC triggers autophagy via stabilizing Sirt1 and attenuates the chemosensitivity of HCC cells. Oncogene. 2017; 36:3528-3540.

22. Gade TP, Tucker E, Nakazawa MS, Hunt SJ, Wong W, Krock B, Weber CN, Nadolski GJ, Clark TW, Soulen MC, Furth EE, Winkler JD, Amaravadi RK, Simon MC. Ischemia induces quiescence and autophagy dependence in hepatocellular carcinoma. Radiology. 2017; 283:702-710.

23. Jiao L, Li DD, Yang CL, Peng RQ, Guo YQ, Zhang XS, Zhu XF. Reactive oxygen species mediate oxaliplatin-induced epithelial-mesenchymal transition and invasive potential in colon cancer. Tumour Biol. 2016; 37:8413-8423.

24. Uchibori K, Kasamatsu A, Sunaga M, Yokota S, Sakurada T, Kobayashi E, Yoshikawa M, Uzawa K, Ueda S, Tanzawa H, Sato N. Establishment and characterization of two 5-fluorouracil-resistant hepatocellular carcinoma cell lines. Int J Oncol. 2012; 40:1005-1010.

25. Ma JL, Zeng S, Zhang Y, Deng GL, Shen H. Epithelialmesenchymal transition plays a critical role in drug resistance of hepatocellular carcinoma cells to oxaliplatin. Tumour Biol. 2016; 37:6177-6184.

26. Giannelli G, Koudelkova P, Dituri F, Mikulits W. Role of epithelial to mesenchymal transition in hepatocellular carcinoma. J Hepatol. 2016; 65:798-808.

27. Saxena M, Stephens MA, Pathak H, Rangarajan A. Transcription factors that mediate epithelial-mesenchymal transition lead to multidrug resistance by upregulating $\mathrm{ABC}$ transporters. Cell Death Dis. 2011; 2:e179.

28. van der Horst G, Bos L, van der Pluijm G. Epithelial plasticity, cancer stem cells, and the tumor-supportive stroma in bladder carcinoma. Mol Cancer Res. 2012; 10:995-1009.

29. Wong YK, Xu C, Kalesh KA, He Y, Lin Q, Wong WS, Shen HM, Wang J. Artemisinin as an anticancer drug: recent advances in target profiling and mechanisms of action. Med Res Rev. 2017; 37:1492-1517.

30. Chaturvedi D, Goswami A, Saikia PP, Barua NC, Rao PG. Artemisinin and its derivatives: a novel class of antimalarial and anti-cancer agents. Chem Soc Rev. 2010; 39:435-454.

31. Zhang CJ, Wang J, Zhang J, Lee YM, Feng G, Lim TK, Shen HM, Lin Q, Liu B. Mechanism-guided design and synthesis of a mitochondria-targeting artemisinin analogue with enhanced anticancer activity. Angew Chem Int Ed Engl. 2016; 55:13770-13774.

32. Wang J, Xu C, Lun ZR, Meshnick SR. Unpacking 'artemisinin resistance'. Trends Pharmacol Sci. 2017; 38:506-511.

33. Lu M, Zessin AS, Glover W, Hsu DS. Activation of the mTOR pathway by oxaliplatin in the treatment of colorectal cancer liver metastasis. PLoS One. 2017; 12:e0169439.

34. Barreto R, Waning DL, Gao H, Liu Y, Zimmers TA, Bonetto A. Chemotherapy-related cachexia is associated with mitochondrial depletion and the activation of ERK1/2 and 
p38 MAPKs. Oncotarget. 2016; 7:43442-43460. https://doi. org/10.18632/oncotarget.9779.

35. Cao J, Xu D, Wang D, Wu R, Zhang L, Zhu H, He Q, Yang B. ROS-driven Akt dephosphorylation at Ser-473 is involved in 4-HPR-mediated apoptosis in NB4 cells. Free Radic Biol Med. 2009; 47:536-547.

36. Li Y, Wang Y, Kong R, Xue D, Pan S, Chen H, Sun B. Dihydroartemisinin suppresses pancreatic cancer cells via a
microRNA-mRNA regulatory network. Oncotarget. 2016; 7:62460-62473. https://doi.org/10.18632/oncotarget.11517.

37. Crespo-Ortiz MP, Wei MQ. Antitumor activity of artemisinin and its derivatives: from a well-known antimalarial agent to a potential anticancer drug. J Biomed Biotechnol. 2012; 2012:247597. 